\author{
Robert A. Gross, MD, PhD, FAAN \\ Editor-in-Chief, Neurology ${ }^{\circledR}$
}

\section{Normal pressure hydrocephalus: How often does the diagnosis hold water? :-}

The authors identified 41 patients who underwent an invasive diagnostic procedure for evaluation of suspected normal pressure hydrocephalus (NPH); 13 were ultimately shunted. NPH was relatively rare, with an incidence approximating that of progressive supranuclear palsy. Although early gait improvement was common, only a third of patients enjoyed continued improvement 3 years later.

See p. 1119; Editorial, p. 1110

\section{Glucose tolerance status and risk of dementia in the} community: The Hisayama Study

A total of 1,017 community-dwelling dementia-free subjects aged $\geq 60$ years who had an oral glucose tolerance test were followed up for 15 years. The risks of dementia and its subtypes, confirmed by neurologic and morphologic findings, increased with elevated 2-hour postload glucose levels.

See p. 1126

Incidence of acquired CNS demyelinating syndromes in a multiethnic cohort of children

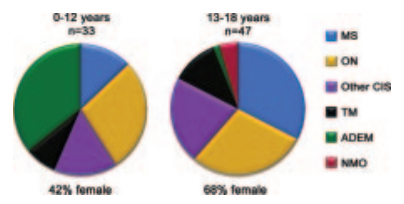

The authors identified 81 incident cases of acquired demyelinating syndromes (ADS) in a cohort of children 0-18 years of age. The incidence rate of pediatric MS was 0.51 and of other forms of ADS was 1.56 per 100,000 person-years. The incidence of ADS and MS was higher in black children compared with white and Hispanic children.

See p. 1143; Editorial, p. 1112

Prolonged survival with valproic acid use in the EORTC/NCIC temozolomide trial for glioblastoma

In this trial, comparing radiotherapy alone with radiotherapy plus temozolomide, myelotoxicity was highest, and outcome the best, in the chemotherapy arm in which patients received valproic acid, compared with no antiepileptic drug or enzymeinducing antiepileptic drugs. Understanding the interaction of temozolomide and valproic acid may result in new treatment strategies for glioblastoma.

See p. 1156
CELEBRATING 60 YEARS OF PUBLICATION

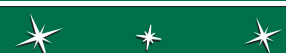

*

From editorialists Wen and Schiff: "While most interest has focused on HDAC inhibitors as radiosensitizers, the lack of a survival benefit when VPA was used with radiation therapy alone in the study by Weller et al. suggests that if there is a synergistic antitumor effect, it may be primarily with temozolomide."

See p. 1114

Systemic chemokine levels, coronary heart disease, and ischemic stroke events: The PRIME Study

After following 9,771 men for 10 years, 2 studies were designed to include 621 first coronary heart disease events and 1,242 controls and 95 first ischemic stroke events and 190 controls. The results demonstrated that higher plasma chemokine concentrations increased the risk of stroke but not of coronary heart disease.

See p. 1165; Editorial, p. 1116

Differential features of carotid and vertebral artery dissections: The CADISP Study

This observational study analyzed 982 cervical artery dissections (CEAD) in consecutive patients to determine whether risk factor profile, baseline features, and outcome of CEAD differed according to the dissection site. The authors observed differences between vertebral artery and internal carotid artery dissections based on risk factors, baseline features, and functional outcome.

See p. 1174

Abnormal tactile temporal discrimination in psychogenic dystonia

Temporal discrimination threshold of tactile stimuli was assessed in 10 patients with psychogenic dystonia, 10 patients with primary torsion dystonia, and 16 control subjects.

Somatosensory dysfunction in psychogenic dystonia might underlie the development of involuntary dystonic postures triggered by psychological and psychiatric factors.

See p. 1191

NB: "Clinical Reasoning: A 34-year-old man with recurrent limb weakness," see p. e68. To check out other Resident \& Fellow submissions, point your browser to http://www.neurology.org and click on the link to the Resident \& Fellow Section.

Podcasts can be accessed at www.neurology.org 


\section{Neurology}

\section{Spotlight on the September 20 Issue}

Robert A. Gross

Neurology 2011;77;1109

DOI 10.1212/WNL.0b013e3182312642

This information is current as of September 19, 2011

\section{Updated Information \&}

Services

Permissions \& Licensing

Reprints including high resolution figures, can be found at: http://n.neurology.org/content/77/12/1109.full

Information about reproducing this article in parts (figures,tables) or in its entirety can be found online at:

http://www.neurology.org/about/about_the_journal\#permissions

Information about ordering reprints can be found online:

http://n.neurology.org/subscribers/advertise

Neurology ${ }^{\circledR}$ is the official journal of the American Academy of Neurology. Published continuously since 1951, it is now a weekly with 48 issues per year. Copyright Copyright (? 2011 by AAN Enterprises, Inc.. All rights reserved. Print ISSN: 0028-3878. Online ISSN: 1526-632X.

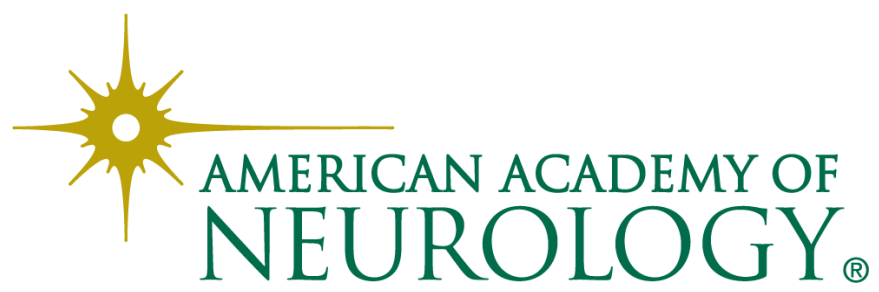

